\title{
Isolation of the subclavian artery associated with chromosome 22q11 deletion
}

A $\mathrm{n}$ interesting report on isolation of the subclavian artery appeared in the recent issue of this journal. ${ }^{1}$ The authors reported 3 patients with interruption of the aortic arch between the carotid arteries ('type B'), isolation of the subclavian artery, and deletion of the chromosome $22 \mathrm{q} 11$. Isolation of the subclavian artery is a rare anomaly. Although the authors discussed only briefly the etiologic significance of isolation of the subclavian artery combined with chromosome $22 \mathrm{ql}$, further discussion is warranted.

In our early study on cardiovascular anomalies associated with tetralogy of Fallot and chromosome $22 \mathrm{q} 11$ deletion, isolation of the subclavian artery was present in 3 out of 22 patients with the deletion, and in none of another 22 patients without the deletion. ${ }^{2}$ Isolation of the subclavian artery was present in another patient with deletion of the chromosome $22 \mathrm{q} 11$ and a normal heart. ${ }^{3}$ This combination suggests that isolation of the subclavian artery is another of the specific features of chromosome $22 \mathrm{q} 11$ deletion.

Chromosome 22q11 deletion causes those cardiovascular anomalies which are related to insufficiency of embryonic neural crest cells. ${ }^{4}$ Neural crest cells are important in septation of the developing ventricular outflow tracts and arterial segments, ${ }^{4}$ and

\section{Reply to Letter}

$\mathrm{W}$ e are pleased that Dr. Momma found our recent report, 'Rare forms of isolation of the subclavian artery: diagnostic and surgical considerations' ${ }^{1}$ of sufficient interest to write a letter to the editor. The gist of Dr. Momma's letter was that the association between deletions in chromosome 22q11 and isolation of the subclavian artery in our 3 patients with interrupted aortic arch 'suggests that isolation of the subclavian artery is another of the specific features persistence and regression of arch arteries. ${ }^{5}$ Isolation of the subclavian artery associated with the chromosome $22 \mathrm{q} 11$ deletion is another piece of evidence confirming the role of neural crest cells in development of the aortic arches.

Kazuo Momma

Professor of Pediatric Cardiology, The Heart Institute of Japan,

Tokyo Women's Medical University, Tokyo, Japan

\section{References}

1. McElhinney DB, Silverman NH, Brook MM, Reddy VM, Hanley FL. Rare forms of isolation of the subclavian artery: echocardiographic diagnosis and surgical considerations. Cardiol Young 1998;8: 344-351.

2. Momma K, Kondo C, Ando M, Matsuoka R, Takao A Tetralogy of Fallot associated with chromosome 22q11 deletion. Am J Cardiol 1995;76: 618-621.

3. Momma K, Kondo C, Matusoka R, Takao A. Cardiac anomalies associated with a chromosome $22 \mathrm{q} 11$ deletion in patients with conotruncal anomaly face syndrome. Am J Cardiol 1996;78: 591-594

4. Kirby ML, Waldo AL. Role of neural crest in congenital heart disease. Circulation 1990;82: 332-340.

5. Waldo KL, Kumiski D, Kirby M. Cardiac neural crest is essential for persistence rather than formation of an arch artery. Develop Dynamics 1996;205: 281-292. of chromosome 22q11 deletion' and serves as 'evidence confirming the role of neural crest cells in development of the aortic arches' (our italics).

For many years, Dr. Momma has been a leader in characterizing the clinical epidemiology of congenital heart disease associated with deletions of chromosome $22 \mathrm{q} 11$ in humans, ${ }^{2-5}$ and of developing animal models of malformations of the ventricular outlet such as are seen in patients with del22q11. ${ }^{6} \mathrm{He}$ has published papers on deletion in 
patients with tetralogy of Fallot, tetralogy with pulmonary atresia, and common arterial trunk, as well as more general investigations of cardiac anomalies in patients with deletions of chromosome 22q11 and so-called 'conotruncal anomaly face syndrome' ${ }^{2-5}$ His experience with this issue is clearly extensive, and the wisdom he has accrued through this experience is to be heeded.

Regarding the ends to which Dr. Momma proposes our report be used, however, we offer several caveats. All 3 of the patients with isolation of subclavian artery in our series had a coexisting interruption of the aortic arch, 1 with a right-sided aortic arch. Interrupted arch and right-sided arch are both highly associated with deletions of chromosome $22 \mathrm{q} 11$ in their own right. ${ }^{7}$ While isolation of the subclavian artery may be associated with deletion more often than not, as Dr. Momma has found in previous reports, ${ }^{2,5}$ it is a bold claim to propose that this lesion 'is another of the specific features of chromosome 22q11 deletion'. Isolation of the subclavian artery is clearly not always associated with deletion, as evidenced by our patient with atrioventricular septal defect, ${ }^{1}$ as well as patients reported by Momma, ${ }^{5}$ and there is limited data on individuals with isolated anomalies of the aortic arch who are asymptomatic and with eusomy of chromosome 22q11. Moreover, isolation of the subclavian artery is a relatively uncommon feature of cardiovascular anomalies associated with $22 \mathrm{q} 11$ deletion, and is exceedingly rare in association with some such anomalies, such as common arterial trunk.

Deletions in chromosome $22 \mathrm{q} 11$ are thought to contribute to the pathogenesis of certain congenital heart defects by disrupting development or migration of neural crest cells that normally contribute to the outlet portion of the heart and the pharyngeal arches. The association between congenital heart defects and 22q11 deletion, however, has not been proven as anything more than an association. That is, the mechanism by which deletion may cause either neural crestopathy or congenital cardiovascular anomalies has not been identified. Gradual progress is being made in this area $^{8-10}$ and in understanding the role of the neural crest in cardiovascular development, ${ }^{11}$ but researchers are also coming to recognize other potential mechanisms by which the cardiovascular lesions commonly associated with del22q11 may be caused by aberrations independent of dysfunction of cells derived from the neural crest. ${ }^{12}$ Moreover, certain forms of congenital heart disease, such as double-outlet right ventricle, are caused by ablation of the neural crest in animal models ${ }^{11}$ but rarely found in association with deletion of chromosome 22q11 in humans. ${ }^{7}$ Thus, until the causal nexus is more firmly established, it is premature to claim that the association between 22q11 deletion and isolation of the subclavian artery in our 3 patients with interrupted arch is 'evidence confirming the role of neural crest cells in development of the aortic arches'.

The intention of this response is not to dissuade investigators from exploring associations between geneotypic and phenotypic features in patients with congenital heart disease, but to advocate for the application of rigorous scientific method. Until we understand, even to an elementary degree, the mechanisms by which the products of the genetic locuses in the DiGeorge critical region of chromosome 22q11 facilitate normal cardiovascular development, and by which deletion leads to abnormal development, there is arguably little benefit to identifying specific anomalies of the aortic arch, for example, that may be associated with this particular chromosomal deletion in small cohorts of patients. Such cohorts are often skewed by selection bias, given the referral-based tertiary case settings in which they are studied, and the lack of inclusion of patients with isolated anomalies, including isolation of the subclavian artery, that may never cause symptoms. Moreover, the clinical utility of screening for deletions among patients anomalies of the outflow tract and arches is limited, as Bristow and Bernstein argued in a recent editorial. ${ }^{13}$ Among patients with these cardiovascular defects, no difference in outcome has been identified between those with and without the deletion.

Ultimately, Dr. Momma's contention is likely to be borne out. The association between branching abnormalities of the aortic arch, including isolation of the subclavian artery, and deletions of chromosome 22 q11 will probably turn out to be causal in nature. Until more compelling mechanistic evidence is discovered, however, let us allow associations to remain simply associations, and not usher them into service, even rhetorically, as confirmatory evidence.

\section{References}

1. McElhinney DB, Silverman NH, Brook MM, Reddy VM, Hanley FL. Rare forms of isolation of the subclavian artery: echocardiographic diagnosis and surgical considerations. Cardiol Young 1998;8: 344-351

2. Momma K, Kondo C, Ando M, Matsuoka R, Takao A. Tetralogy of Fallot associated with chromosome $22 q 11$ deletion. Am J Cardiol 1995;76: 618-621

3. Momma K, Kondo C, Matsuoka R. Tetralogy of Fallot with pulmonary atresia associated with chromosome $22 \mathrm{q} 11$ deletion. J Am Coll Cardiol 1996;27: 198-202 
4. Momma K, Ando M, Matsuoka R. Truncus arteriosus communis associated with chromosome $22 \mathrm{q} 11$ deletion. J Am Coll Cardiol 1997;30: 1067-1071

5. Momma K, Kondo C, Matsuoka R, Takao A. Cardiac anomalies associated with a chromosome $22 \mathrm{ql} 1$ deletion in patients with conotruncal anomaly face syndrome. Am $\mathrm{J}$ Cardiol 1996;78: 591-594

6. Momma K, Ando M, Takao A, Miyagawa-Tomita S. Fetal cardiovascular morphology of truncus arteriosus with or without truncal valve insufficiency in the rat. Circulation 1991;83: 2094-2100

7. Goldmuntz E, Clark BJ, Mitchell LE, Jawad AF, Cuneo BF, Reed L, McDonald-McGinn D, Chien P, Feuer J, Zackai EH, Emanuel BS, Driscoll DA. Frequency of $22 \mathrm{q} 11$ deletions in patients with conotruncal defects. J Am Coll Cardiol 1998;32: $492-498$

8. Wilming LG, Snoeren CA, van Rijswijk A, Grosveld F, Meijers C. The murine homologue of HIRA, a DiGeorge syndrome candidate gene, is expressed in embryonic structures affected in human CATCH22 patients. Hum Mol Genet 1997;6: $247-258$
9. Gard V, Yamagishi H, Thomas TK, Srivastava D. COT-22, a candidate gene for the CATCH-22 syndrome. Circulation 1998;98(suppl I): I-757

10. Gottlieb S, Emanuel BS, Driscoll DA, Sellinger B, Wang Z, Roe B, Budarf ML. The DiGeorge syndrome minimal critical region contains a goosecoid-like (GSCL) homeobox gene that is expressed early in human development. Am J Hum Genet 1997;60: 1194-1201

11. Kirby ML, Waldo KL. Neural crest and cardiovascular patterning. Circ Res 1995;77: 211-215

12. Thomas T, Kurihara H, Yamagishi H, Kurihara Y, Yazaki Y, Olson EN, Srivastava D. A signalling cascade involving endothelin-1, dHAND and Msx1 regulates development of neural-crest-derived branchial arch mesenchyme. Development 1998;125: 3005-3014

13. Bristow JD, Bernstein HS. Counseling families with chromosome 22q11 deletions: the catch in CATCH-22. J Am Coll Cardiol 1998;32: 499-501 